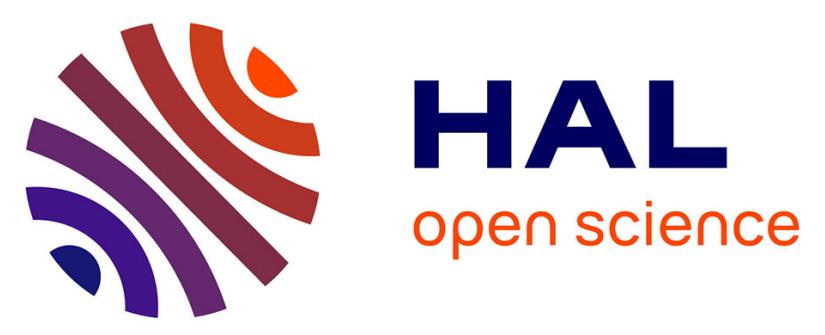

\title{
Nonaqueous capillary electrophoretic behavior of 2-aryl propionic acids in the presence of an achiral ionic liquid
}

Yannis François, Anne Varenne, Emilie Juillerat, Anne-Catherine Servais, Patrice Chiap, Pierre Gareil

\section{- To cite this version:}

Yannis François, Anne Varenne, Emilie Juillerat, Anne-Catherine Servais, Patrice Chiap, et al.. Nonaqueous capillary electrophoretic behavior of 2-aryl propionic acids in the presence of an achiral ionic liquid. Journal of Chromatography A, 2007, 1138 (1-2), pp.268-275. 10.1016/j.chroma.2006.10.063 . hal-02988933

\section{HAL Id: hal-02988933 \\ https://hal.science/hal-02988933}

Submitted on 4 Nov 2020

HAL is a multi-disciplinary open access archive for the deposit and dissemination of scientific research documents, whether they are published or not. The documents may come from teaching and research institutions in France or abroad, or from public or private research centers.
L'archive ouverte pluridisciplinaire HAL, est destinée au dépôt et à la diffusion de documents scientifiques de niveau recherche, publiés ou non, émanant des établissements d'enseignement et de recherche français ou étrangers, des laboratoires publics ou privés. 
4 7

8

9 16 (1) 6 2

\section{A CHEMOMETRIC APPROACH}

Yannis François ${ }^{1}$, Anne Varenne ${ }^{1}$, Emilie Juillerat ${ }^{1}$, Anne-Catherine Servais ${ }^{2}$, Patrice Chiap ${ }^{2}$, Pierre Gareil ${ }^{1 *}$

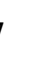
8

${ }^{1}$ Laboratory of Electrochemistry and Analytical Chemistry, UMR CNRS 7575, ENSCP, 11 rue Pierre et Marie Curie, 75231 Paris cedex 05, France

${ }^{2}$ Department of Analytical Pharmaceutical Chemistry, Institute of Pharmacy, University of Liège, B-4000 Liège, Belgium

Running title: NACE of 2-arylpropionic acids in the presence of an ionic liquid

17 Keywords: ionic liquids, nonaqueous capillary electrophoresis, experimental design, ionpairing

* To whom correspondence should be addressed.

E-mail: pierre-gareil@enscp.fr. Tel : 331554263 71. Fax: 33144276750 


\section{Abstract}

Ionic liquids (ILs) appear really attractive as electrolyte additives in nonaqueous capillary electrophoresis (NACE). These salts may offer new possibilities of interactions to modulate analyte effective mobilities. The presence of 1-n-butyl-3-methylimidazolium bis(trifluoromethanesulfonyl)imide (BMIMNTf $\left.\mathrm{B}_{2}\right)$ in acetonitrile/alcohol background electrolytes (BGEs) was investigated in this work. The aim of this study was to elucidate the influence of the IL concentration on the electrophoretic behavior of four arylpropionic acids and to identify the interactions between the analytes and the IL cation. The influence on mobility of the IL concentration, the nature and the proportion of the organic solvents, and the concentration of the ionic components of the BGE was first studied by an univariate approach. A four-factor D-optimal experimental design was then applied to provide a deeper insight into analyte interaction with IL cation present both free in BGE and adsorbed onto the capillary wall. 


\section{Introduction}

40

41

42

A great interest is being drawn towards ionic liquids (ILs) as alternatives for conventional molecular solvents used in organic synthesis and catalytic reactions [1]. They supplement the family of "green solvents" including water and supercritical fluids. Among these, room temperature ionic liquids are defined as materials containing only ionic species and having a melting point lower than $298 \mathrm{~K}$. They exhibit many interesting properties such as negligible vapor pressure, low melting point, large liquid range, unique solvation ability and overall, the versatility of their physico-chemical properties makes them really attractive. They have been proposed as solvents in chemical reactions [2-4], multiphase bioprocess operations [5] and liquid-liquid separations [6,7], electrolytes for batteries and fuel cells [8], stationary phases in gas chromatography [9-12], mobile phase additives in liquid chromatography [13-15] and electrolyte additives in capillary electrophoresis (CE) [16-23].

During these last years, a great attention has been paid to the relevance of these new media for CE and many efforts have been directed toward the understanding of the separation mechanisms involved in IL-containing background electrolytes (BGEs). Nevertheless, the knowledge of these mechanisms remains very limited. Yanes et al. [16,17] suggested that when dialkylimidazolium-based ILs are used as additives to BGEs, positively charged imidazolium groups intervene both in the electrolyte bulk and on the capillary wall. They explained this phenomenon by the coating of the capillary wall by IL cations. More recently, Vaher et al. [18-22], employed dialkylimidazolium-based ILs as electrolytes in nonaqueous CE (NACE) for the separation of water-insoluble dyes and mixtures of phenols, and explained the results by a heteroconjugation interaction between the IL anion and the analyte.

For many years, nonaqueous media have been introduced to enlarge the field of applications in CE. The use of nonaqueous electrolytes in CE has proven to be a very powerful tool for water insoluble compounds. The fact that ILs are easily soluble in a number of molecular solvents $\left(\varepsilon_{r}>6\right)$ has opened a new way in the search for new interaction systems, especially the ion-pair or ion-dipole formation. Indeed, exploiting ion-pairing has proven to be an interesting approach for the chiral and achiral separations of ionisable analytes in NACE, by addition of a suitable counter-ion to the BGE [24, 25].

Within the framework of a study of new chiral IL selectors for enantiomeric separations, the aim of this preliminary work was to elucidate the interactions between an achiral IL and a class of chiral anionic compounds. More specifically, the influence of the concentration of 1n-butyl-3-methylimidazolium bis(trifluoromethanesulfonyl)imide (BMIMNTf 2 , Figure 1) on 
the electrophoretic behavior in nonaqueous media of a series of four arylpropionic acids (also named profens, see Figure 1) was investigated. This work was conducted using an experimental design approach. The first step of this work was to study, by an univariate approach, the factors affecting the electrophoretic mobility of profens, in order to explore the experimental domain and to determine its limits. An experimental design was then applied to provide a deeper insight into a possible ion-pair formation between the IL cation and the analytes.

\section{Experimental}

\subsection{Chemicals and reagents}

1-butyl-3-methylimidazolium bis(trifluoromethanesulfonyl)imide (BMIM NTf 2 ( $(\geq 99 \%)$ was a gift from Institut Français du Pétrole (Solaize, France). Methanol (GC grade, 99.9\% purity), ethanol (GC grade, > 99.8\%) and sodium acetate were purchased from Prolabo (Fontenaysous-Bois, France). Acetonitrile (Chromasolv grade) was obtained from Riedel de Haën (Seelze, Germany). Glacial acetic acid (> 99\%) and formamide (> 99\%) were supplied by Sigma-Aldrich (St. Louis, MO, USA). 2-Arylpropionic acids (carprofen, suprofen, ketoprofen and naproxen) were a gift from Rhone-Poulenc-Rorer (Vitry-sur-Seine, France).

\subsection{Capillary electrophoresis instrumentation}

All experiments were performed with a $\mathrm{HP}^{3 \mathrm{D}} \mathrm{CE}$ (Agilent Technologies, Waldbronn, Germany) capillary electrophoresis system. This apparatus automatically realized all the steps of the measurement protocols, including capillary conditioning, sample introduction, voltage application and diode array detection, and allows to run unattended method sequences. A CE Chemstation (Agilent Technologies, Waldbronn, Germany) was used for instrument control, data acquisition and data handling. Polymicro bare fused-silica capillaries of $50 \mu \mathrm{m}$ I.D. were obtained from Photonlines (Marly-le-Roi, France). They were used in $35 \mathrm{~cm}$ total length (26.5 $\mathrm{cm}$ to detection). BGEs were made up with sodium acetate $(5,23.3,32.5,41.7$ and $60 \mathrm{mM})$ and proper concentration of acetic acid to provide an aqueous $\mathrm{pH}$ of 5.0. The methanol or ethanol-acetonitrile mixtures were prepared by volumic mixing in 50, 66.7, 75, 83.3 and 100 $\%$ ethanol or methanol proportions. Analytes were detected by UV absorbance at 200, 230, 240, 254 and $300 \mathrm{~nm}$, according to cases. Formamide (0.001\% (v/v) in the BGE) was used as 
neutral marker to determine the electroosmotic mobility. The sample solutions were prepared by dissolving each analyte at a concentration of ca $0.5 \mathrm{mM}$ in methanol. Samples were introduced hydrodynamically by successively applying a 30 mbar pressure for $3 \mathrm{~s}$ (approximately, $4 \mathrm{~nL}$ ) to the neutral marker, BGE and sample vials. New capillaries were conditioned by successive flushes with $1 \mathrm{M}$ and $0.1 \mathrm{M} \mathrm{NaOH}$ and then with water under a pressure of $935 \mathrm{mbar}$, for $10 \mathrm{~min}$ each. The temperature in the capillary cartridge was set at 25 ${ }^{\circ} \mathrm{C}$. The acquisition rate was 10 points / s. Capillaries were rinsed with water and dried by air when not in use.

\subsection{Experimental design}

The elaboration of the experimental design and all statistical calculations were performed by means of Modde Software Version 6.0 (Umetri AB, Umea, Sweden).

\section{Results and discussion}

The aim of this work was to study the influence of the presence of BMIM $\mathrm{NTf}_{2}$ ionic liquid on the mobility of a series of 2-arylpropionic acids in nonaqueous media. An experimental design was implemented to better characterize the actual influence of this parameter under various electrolyte conditions without alteration caused by the other factors. In addition to the IL concentration, three other parameters were selected to be incorporated in the experimental design: the nature of the alcohol in the alcohol-acetonitrile mixture, the percentage of the alcohol in the mixture and the salt concentration in the buffer $\mathrm{pH}$. Acetonitrile-methanol mixtures have often been reported to constitute favorable solvent media for NACE separations [26,27], which can be explained by the quite different physico-chemical properties of these solvents, mainly with respect to their hydrogen bond donor and dipolar interaction ability and the low viscosity of their mixtures. Acetonitrile-methanol mixtures were therefore retained for this study. Acetonitrile-ethanol mixtures were also considered to investigate the influence of the nature of the alcohol, ethanol having a lower dielectric constant $\left(\varepsilon_{r}=25\right)$ than methanol $\left(\varepsilon_{\mathrm{r}}=33\right)$ [28] (Table 1) and thus favoring ion-pair interactions. In both cases, the alcohol was selected as the main solvent because of its ability to solubilize a large number of cyclodextrins, in view of subsequent work on chiral separations. As a pH buffer, acetic acid / sodium acetate mixtures, which would provide an aqueous $\mathrm{pH}$ of 5.0, were used. The $\mathrm{pH}$ value was chosen in order to obtain predominantly charged profens (see aqueous pKa in Figure 1). The experimental field for the sodium acetate 
concentration and $\mathrm{BMIMNTf}_{2}$ concentration was limited to keep electric current intensity within reasonable values with respect to Joule heating. For the sake of example, Figure 2 shows an electropherogram obtained under conditions belonging to the explored experimental domain and presenting a full separation of the four profens.

\subsection{Univariate approach}

The parameters amenable to influence the electrophoretic mobility of 2-arylpropionic acids in NACE were first examined using an univariate approach to explore the experimental domain and check the pertinency of its limits, before undertaking a multivariate study. The results of this preliminary study are given in Table 2. As expected, much lower electroosmotic mobilities were observed in EtOH-ACN mixtures, compared to $\mathrm{MeOH}-\mathrm{ACN}$ mixtures. This behavior is due to the influence of the dielectric constant $\left(\varepsilon_{r}\right)$ to viscosity $(\eta)$ ratio for each alcohol, in agreement with the Helmotz-Smoluchowski relationship:

$$
\mu_{e o}=-\frac{\varepsilon_{r} \varepsilon_{o} \zeta}{\eta}
$$

in which $\varepsilon_{0}$ is the vacuum permittivity and $\zeta$ the zeta potential. In the same way, the electrophoretic mobilities of the four profens decreased on going from a MeOH-ACN to a EtOH-ACN medium. The effect of the alcohol proportion in the BGE has also been studied. The experimental field was limited to (50-100 \% v/v) alcohol proportions because of solubility limitations for acetate buffer in EtOH-ACN mixtures of lower alcohol contents. The results given in Table 2 show a pronounced increase in electroosmotic mobilities by increasing ACN percentage. This variation should be due to both an increase in dielectric constant to viscosity ratio and a decrease in viscosity (see equation (1)). Simultaneously, a significant increase in electrophoretic mobility was also obtained for each profen, which also, should be related to the decrease in medium viscosity, although alteration of the ionization degree of the analytes can be possible as well, due to slight modifications of analyte and buffer pKa. The influence of sodium acetate concentration was explored between 5 and 60 $\mathrm{mM}$. It should be noted that this parameter cannot be assimilated to electrolyte ionic strength for two reasons: (i) the IL concentration added to the electrolyte should contribute to different extent to ionic strength, according to the sodium acetate and IL concentrations, and (ii) the ionization rate of sodium acetate and IL in the electrolyte medium were unknown and so was their contribution to overall ionic strength. In spite of this, however, it can be admitted that 
ionic strength varied in the same direction as sodium acetate concentration. Finally, the results from Table 2 show a fall of electroosmotic mobility by increasing sodium acetate concentration, which, in agreement with expectations from the literature, was due to the narrowing of the double layer thickness at the capillary wall. Likewise and as expected, a decrease in profen electrophoretic mobilities (absolute values) was observed upon increasing the salt concentration of the buffer.

As for the IL concentration, an increase within the $0-20 \mathrm{mM}$ range first resulted in a strong decrease of the electroosmotic mobility. This already reported phenomenon [17,19] was explained by the adsorption of the ionic liquid cation to the capillary wall, thus creating a dynamic coating. At these IL concentrations, the viscosity effect on the IL - solvent mixture was negligible [30]. The electrophoretic mobilities of profens also underwent a marked decrease (in absolute value) upon increasing IL concentration.

\subsection{Multivariate approach}

After having checked by using an univariate approach that the experiments can be realized and exploited within the limits of the experimental domain, an approach based on the methodology of experimental design was developed to estimate the main effects of the different factors, as well as possible first-order interactions and quadratic terms and determine those having a significant effect on mobilities. Table 3 gives the matrix of the various trials realized. It is to note that one factor (alcohol nature) was discrete, whereas the other three were continuous. A D-optimal design was selected [31] and elaborated by Modde software, consisting in 25 experiments to be performed in random order. In this design, the three continuous factors were arranged into five levels and the central point was repeated thrice. This design allowed to maximize the answer variability predicted by the model (so-called $\mathrm{Q}_{2}$ coefficient). The Modde software was also used to conduct all statistical calculations.

The relationship between the response (profen electrophoretic mobility) and the factors was defined as a quadratic, multi-linear regression model. Insofar as one factor was discrete, this model included 18 coefficients [32,33] for the constant term $\left(\beta_{0}\right)$, the five main effects $\left(\beta_{i}\right)$, the three quadratic terms $\left(\beta_{\mathrm{ii}}\right)$ and the nine interaction terms $\left(\beta_{\mathrm{ij}}\right.$, with $\left.\mathrm{i} \neq \mathrm{j}\right)$, as indicated in equation (2): 


$$
Y=\beta_{0}+\beta_{1} X_{1}+\beta_{2} X_{2}+\beta_{3} X_{3}+\beta_{4-\mathrm{MeOH}} X_{4-\mathrm{MeOH}}+\beta_{4-\mathrm{EtOH}} X_{4-\mathrm{EtOH}}+\beta_{11} \mathrm{X}_{1}^{2}+\beta_{22} \mathrm{X}_{2}{ }^{2}+
$$

$$
\beta_{33} X_{3}^{2}+\beta_{12} X_{1} X_{2}+\beta_{13} X_{1} X_{3}+\beta_{14-\mathrm{MeOH}} X_{1} X_{4-\mathrm{MeOH}}+\beta_{14-\mathrm{EtOH}} X_{1} X_{4-\mathrm{EtOH}}+\beta_{23} X_{2} X_{3}+\beta_{24-}
$$

$$
\mathrm{MeOH}_{2} \mathrm{X}_{4-\mathrm{MeOH}}+\beta_{24-\mathrm{EtOH}} \mathrm{X}_{2} \mathrm{X}_{4-\mathrm{EtOH}}+\beta_{34-\mathrm{MeOH}} \mathrm{X}_{3} \mathrm{X}_{4-\mathrm{MeOH}}+\beta_{34-\mathrm{EtOH}} \mathrm{X}_{3} \mathrm{X}_{4-\mathrm{EtOH}}+\varepsilon
$$

where $Y$ stand for profen electrophoretic mobility, $\mathrm{X}_{1}$ for the concentration of ionic liquids,

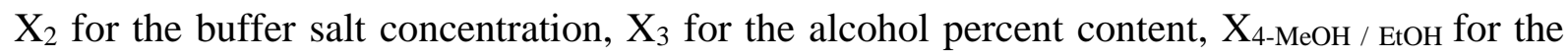
alcohol nature and $\varepsilon$ for the error term.

This equation was solved by taking into account the reduced values described in Table 3 . In order to demonstrate the validity of the fitted models, Table 4 presents the $\mathrm{R}^{2}$ and $\mathrm{Q}^{2}$ values obtained for each compound. $\mathrm{R}^{2}$ expresses the percent of the variation of the response explained by the model. A high $\mathrm{R}^{2}$ is a necessary condition for a good model, but it is not sufficient. A useful model should also have a large $\mathrm{Q}^{2}$, which represents the variation of the response predicted by the model. The reproducibility parameter was also considered. It expresses the variation of the response under the same conditions (at the center points) compared to the total variation of the response. As shown in Table 4, it is very close to 1 , which means that the pure error is very weak. According to these results, the adequacy of the models is confirmed.

218 Table 5 gives the different coefficients ( $\beta$ values) obtained for the model. When the p-value is less than 0.05 (in bold-face type), the $\beta$ value is statistically different from 0 at the $95 \%$ confidence level and therefore the factor associated to this coefficient has a significant influence on mobility [32,33]. It then clearly appeared that the only significant terms at the 95 $\%$ confidence level in equation (2) were among the main and quadratic terms.

A graphical representation of the statistical significance of the effects and their interactions for suprofen is shown in Fig. 3, which directly displays $\beta$ values on the Y-axis and the confidence intervals at $95 \%$ level. Figure 3 again clearly showed that none of the first-order interactions between the selected parameters was significant.

\subsection{Evaluation of factor effects}

228 Regarding the different coefficients and their statistical significance, it first appeared that similar electrophoretic behaviors were followed by the four profens, by considering $\beta_{1}$ coefficient for naproxen and $\beta_{11}$ coefficient for ketoprofen as statistically significant at the $10 \%$ significance level. The following discussion was therefore mainly conducted without 
mentioning the nature of the profen and only the response surface plots for the electrophoretic

233 mobility of suprofen were presented (Figure 4). For each response surface plot, two factors

234 out of the four ones were represented on the $\mathrm{X}$ - and $\mathrm{Y}$-axes, while the third one and the nature

235 of the alcohol were fixed. As can be seen from Figure 4, the profen electrophoretic mobilities

236 (absolute values) are higher in $\mathrm{MeOH}$ media than in $\mathrm{EtOH}$ media. This behavior can be

237 mainly explained by both the lower viscosity of $\mathrm{MeOH}(\eta=0.54)$ with respect to $\mathrm{EtOH}(\eta=$

238 1.09) and the higher dielectric constant of $\mathrm{MeOH}\left(\varepsilon_{\mathrm{r}}=33\right)$ with respect to $\mathrm{EtOH}\left(\varepsilon_{\mathrm{r}}=25\right)$,

239 thus reducing possible contribution of ion-pairing.

240 As can be seen from Figures 4A, B, E and F, electrophoretic mobilities pass through a 241 minimum at a specific alcohol proportion (around 80\%). This variation was mainly due to 242 those of solvent viscosity and dielectric constants.

243 Figures 4A-D show that an increase in the buffer salt concentration leads to a decrease of the 244 profen electrophoretic mobilities, which can be qualitatively attributed to either classical ionic 245 strength effects or increasing ion-pairing effects between anionic profens and sodium cation 246 in these nonaqueous media.

247 Profen electrophoretic mobilities (absolute values) pass through a maximum for a given IL 248 concentration (around $7 \mathrm{mM}$ ) (cf. Figures 4C-F). Such a behavior was not anticipated from a 249 simple possible interaction between anionic profens and IL cation present in the BGE since it 250 would have led to a monotonous decrease in profen electrophoretic mobilities (absolute 251 values). Instead, it may rather be explained by competitive interactions between profen and 252 the IL cation adsorbed onto the capillary wall or the free IL cation present in the BGE, as 253 depicted in Figure 5. In effect, for the lowest IL concentrations, a chromatographic-like 254 interaction between the profens and the IL cations adsorbed onto the capillary wall should 255 lead to increased migration times which, in counter-electroosmotic migration mode, may be 256 interpreted as an apparent increase in electrophoretic mobility (absolute value). Conversely, 257 for IL concentrations higher than ca $7 \mathrm{mM}$, the decrease in electrophoretic mobility suggested 258 that an ion-pair interaction between the anionic profen and the free IL cations in the BGE 259 might become prevailing, after the capillary wall had been fully coated with IL cation. 
262 This work provided a deeper insight into the physico-chemical interactions coming into play 263 between a series of arylpropionic acids, almost fully dissociated, and a water-insoluble, 264 imidazolium-based ionic liquid in NACE. Using a statistical design approach, the 265 electrophoretic mobility of these analytes was modelled as a function of ionic liquid 266 concentration, buffer salt concentration, composition of the alcohol-acetonitrile mixture and 267 nature of the alcohol constituting the BGE. From the obtained response surface plots, 268 competitive interactions of ion-pair type between anionic analytes and ionic liquid cation, 269 either free in solution or adsorbed onto the capillary wall, were proposed. The results from 270 this work lent support to the evaluation of the enantiorecognition of arylpropionic acids by 271 chiral ionic liquids in NACE, that has just been investigated in our group and will be reported 272 soon.

273

274 


\section{References}

276 [1] P. Wasserscheidt, T. Weldon, Ionic Liquids in Synthesis, Wiley-VCH, New York, 2003.

277 [2] J. Dupont, R.F. de Souza, P.A.Z. Suarez, Chem. Rev. 102 (2002) 3667.

278 [3] P. Wasserscheidt, W. Keim, Angew. Chem. Int. Ed. 39 (2000) 3772.

279 [4] M.J. Earle, K.R. Seddon, Pure Appl. Chem. 72 (2000) 1391.

280 [5] S.G. Cull, J.D. Holbrey, V. Vargas-Mora, K.R. Seddon, G.J. Lye, Biotechnol. Bioeng. 69 (2000) 227.

281 [6] J.G. Huddleston, H.D. Willauer, R.P. Swatloski, A.E. Visser, R.D. Rogers, Chem. Comm. (1998) 1765.

282 [7] A.G. Fadeev, M.M. Meagher, Chem. Comm. (2001) 295.

283 [8] A.E. Visser, R.P. Swatloski, R.D. Rogers, Green Chem. 2 (2000) 1.

284 [9] F. Pachole, H.T. Butler, C.F. Poole, Anal. Chem. 54 (1982) 1938.

285 [10] D.W. Armstrong, J.L. Andersen,J. Ding, T. Welton, J. Am. Chem. Soc. 124 (2002) 14247.

286 [11] A. Berthod, L. He, D.W. Armstrong, Chromatographia 53 (2000) 63.

287 [12] A. Heintz, D.W. Kulikov, S.P. Verevkin, J. Chem. Eng. Data 47 (2002) 894.

288 [13] L. He, W. Zhang, L. Zhao, X. Liu, S. Jiang, J. Chromatogr. A 1007 (2003) 39.

289 [14] R. Kaliszan, M.P. Marszall, M.J. Markuszewski, T. Baczek, J. Pernak, J. Chromatogr. A 1030 (2004) 263.

290 [15] X. Xiao, L. Zhao, X. Liu, S. Jiang, Anal. Chim. Acta 519 (2004) 207.

291 [16] E.G. Yanes, S.R. Gratz, A.M. Stalcup, The Analyst 125 (2000) 1919.

292 [17] E.G. Yanes, S.R. Gratz, M.J. Baldwin, S.E. Robinson, A.M. Stalcup, Anal. Chem. 73 (2001) 3838.

293 [18] M. Vaher, M. Koel, M. Kaljurand, Chromatographia 53 (2001) S-302.

294 [19] M. Vaher, M. Koel, M. Kaljurand, Electrophoresis 23 (2002) 426.

295 [20] M. Vaher, M. Koel, M. Kaljurand, J. Chromatogr. A 979 (2002) 27.

296 [21] R. Kuldvee, M. Vaher, M. Koel, M. Kaljurand, Electrophoresis 24 (2003) 1627.

297 [22] M. Vaher, M. Kaljurand, J. Chromatogr. A 990 (2003) 225.

298 [23] S.M Mwongela, A. Numan, N.L. Gill, R.A. Agbaria, I.M. Warner, Anal. Chem. 75 (2003) 6089.

299 [24] M.L. Riekkola, M. Jussila, S.P. Porras, I.E. Valko, J. Chromatogr. A 892 (2000) 155.

300 [25] M. Lämmerhofer, J. Chromatogr. A 1068 (2005) 3.

301 [26] S. Descroix, A Varenne, L. Geiser, S. Cherkaoui, J.L. Veuthey, P. Gareil, Electrophoresis, 24 (2003) 1577.

302 [27] S. Cherkaoui, J.L. Veuthey, J. Chromatogr. A 874 (2000) 121.

303 [28].Y. Marcus, Ion Solvation, Wiley, New York, 1985.

304 [29] F. Lelièvre, P. Gareil, J. Chromatogr. A 735 (1996) 311.

305 [30] Y. Francois, K. Zhang, A. Varenne, P. Gareil, Anal. Chim. Acta 562 (2006) 164.

306 [31] A-C. Servais, M. Fillet, P. Chiap, W. Dewé, P. Hubert, J. Crommen, J. Chromatogr. A 1068 (2005) 143

307 [32] User's Guide to MODDE ${ }^{\circledR} 4.0$, Graphical Software for Design of Experiments, Umetri AB, Umea, Sweden.

308 [33] D.L. Massart, B.G.M. Vandeginste, S.N. Deming, Y. Michotte, L. Kaufman, Data handling in Science and

309 Technology, volume 2, Chemometrics : a textbook, B.G.M. Elsevier, Amsterdam, 1988. 
<smiles>CC(C(=O)O)c1ccc2c(c1)[nH]c1ccc(Cl)cc12</smiles>

\section{CARPROFEN}

(pKa 4.29)<smiles>CC(C(=O)O)c1cccc(C(=O)c2ccccc2)c1</smiles>

\section{KETOPROFEN}

(pKa 4.03)<smiles>COc1ccc2cc(C(C)C(=O)O)ccc2c1</smiles>

\section{NAPROXEN}

(pKa 4.26)

\section{SUPROFEN \\ (pKa 4.00)}

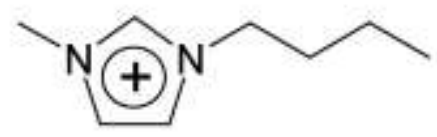

\section{BMIM NTf 2}

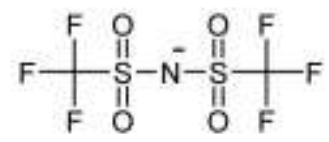

318 Figure 1: Structures of the studied arylpropionic acids and ionic liquid 1-butyl-3-

319 methylimidazolium bis(trifluoromethanesulfonyl)imide (BMIM NTf 2 ). pKa values at 26-27

${ }^{\circ} \mathrm{C}$ from [29] 


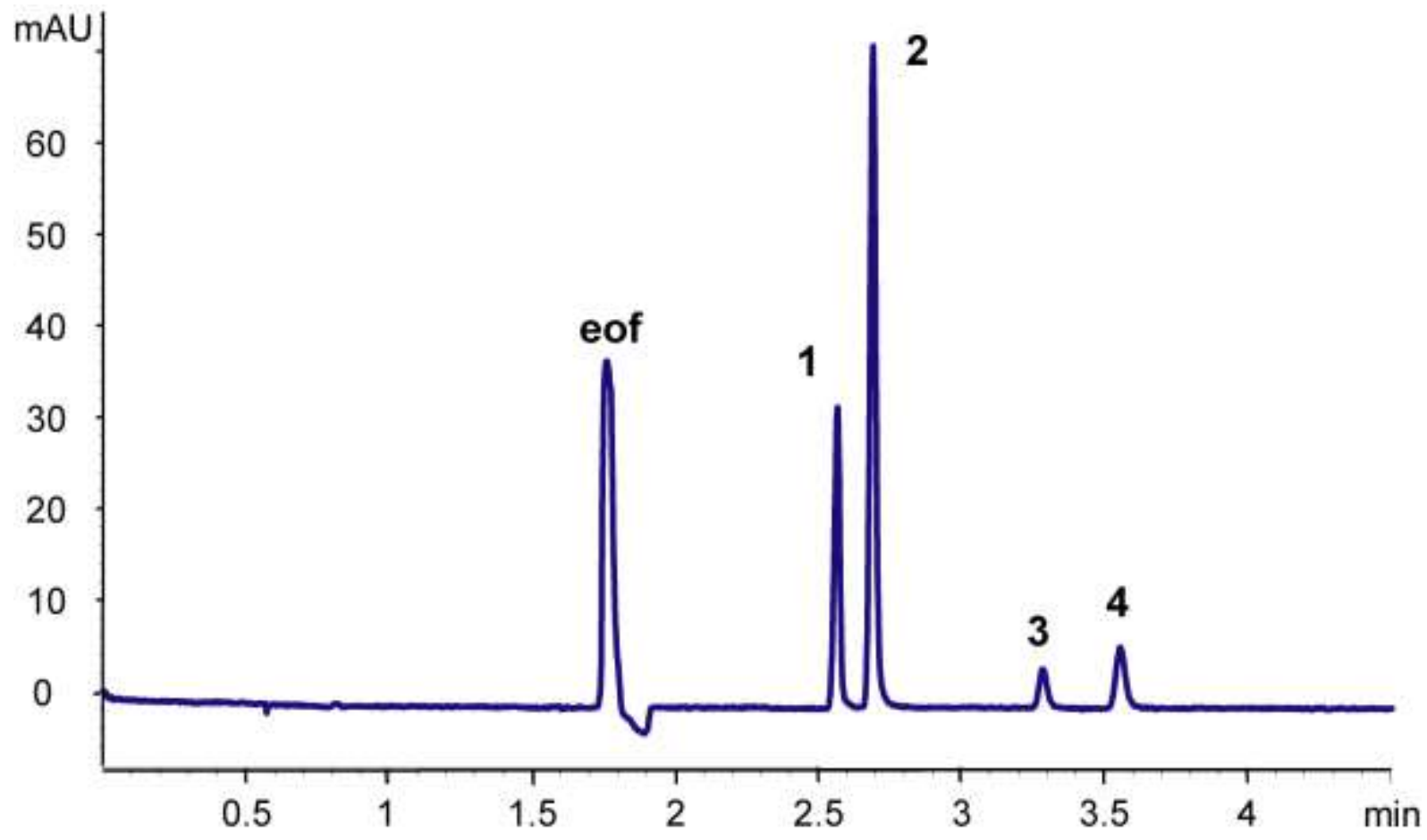

322 Figure 2: Electropherogram of a standard mixture of the model 2-arylpropionic acids.

323 Fused silica capillary, $50 \mu \mathrm{m}$ i.d. $35 \mathrm{~cm}$ (effective length, $26.5 \mathrm{~cm}$ ). Electrolyte: $27.3 \mathrm{mM}$

324 acetic acid, $60.0 \mathrm{mM}$ sodium acetate buffer, ${ }^{{ }_{w}} \mathrm{pH} 5.0$ containing $5 \mathrm{mM} \mathrm{BMIMNTf}_{2}$ in 325 (50:50, v/v) MeOH-ACN mixture. Applied voltage: $20 \mathrm{kV}$. Temperature: $25{ }^{\circ} \mathrm{C}$. UV 326 absorbance at $230 \mathrm{~nm}$. Hydrodynamic injection (30 mbar, $3 \mathrm{~s}$ ). Sample and identification: 327 (eof) electroosmotic flow, (1) suprofen, (2) ketoprofen, (3) naproxen, (4) carprofen $0.5 \mathrm{mM}$ 328 each in $\mathrm{MeOH}$.

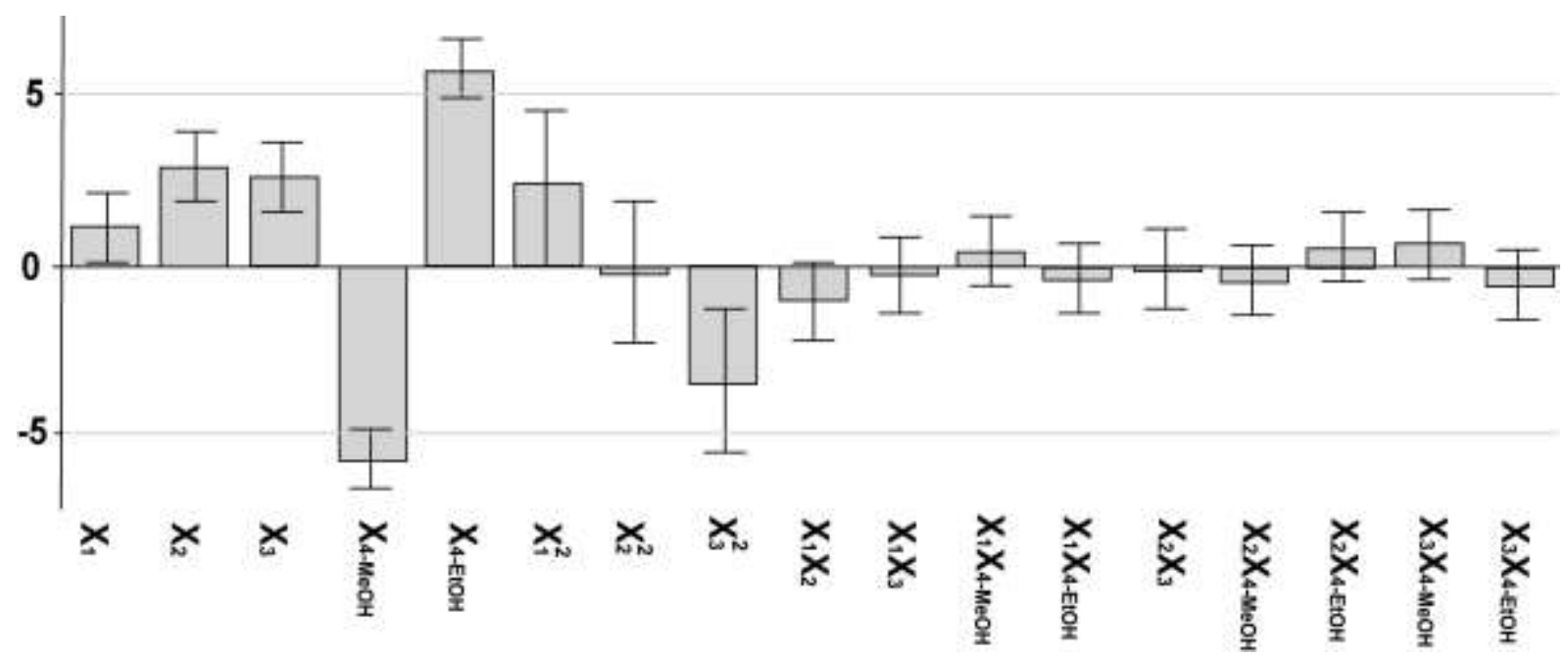

331 Figure 3: Histogram representation of the model coefficients ( $\beta$ values) and their confidence interval at $95 \%$ for the case of suprofen. 
$334\left(\mathrm{X}_{2}\right)$, the alcohol proportion $\left(\mathrm{X}_{3}\right)$ and the nature of the alcohol $\left(\mathrm{X}_{4}\right)$.

$\mathrm{MeOH}$
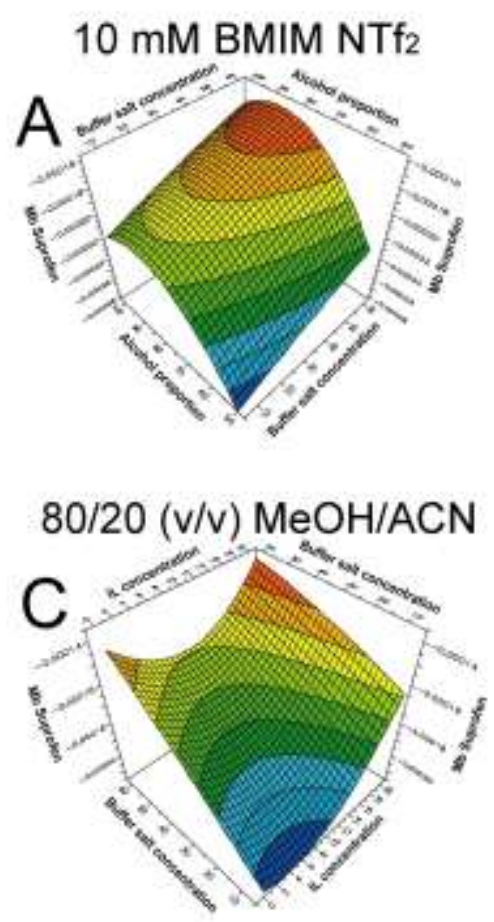

$5 \mathrm{mM}$ buffer salt concentration

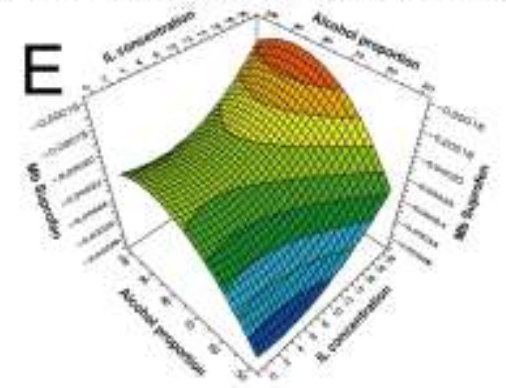

\section{$\mathrm{EtOH}$}
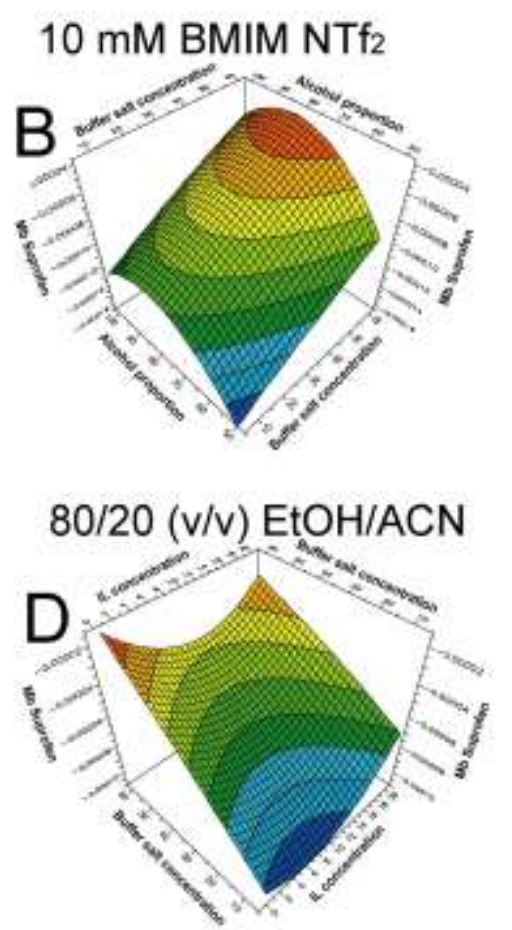

$5 \mathrm{mM}$ buffer salt concentration

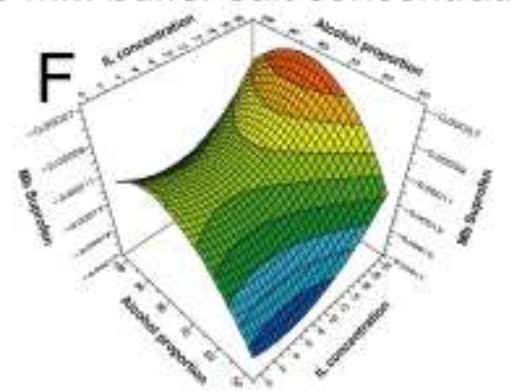

338 Figure 4: Response surface plots for the electrophoretic mobility of suprofen as a function of the nature of the alcohol $(\mathrm{MeOH}, \mathrm{EtOH})$ introduced in the $\mathrm{BGE}$ and $(\mathrm{A}, \mathrm{B})$ the alcohol percent and the buffer salt concentration for a given IL concentration ; $(\mathrm{C}, \mathrm{D})$ the buffer salt concentration and the IL concentration for a given solvent mixture composition ; (E,F) the alcohol percent and the IL concentration for a given buffer salt concentration. 

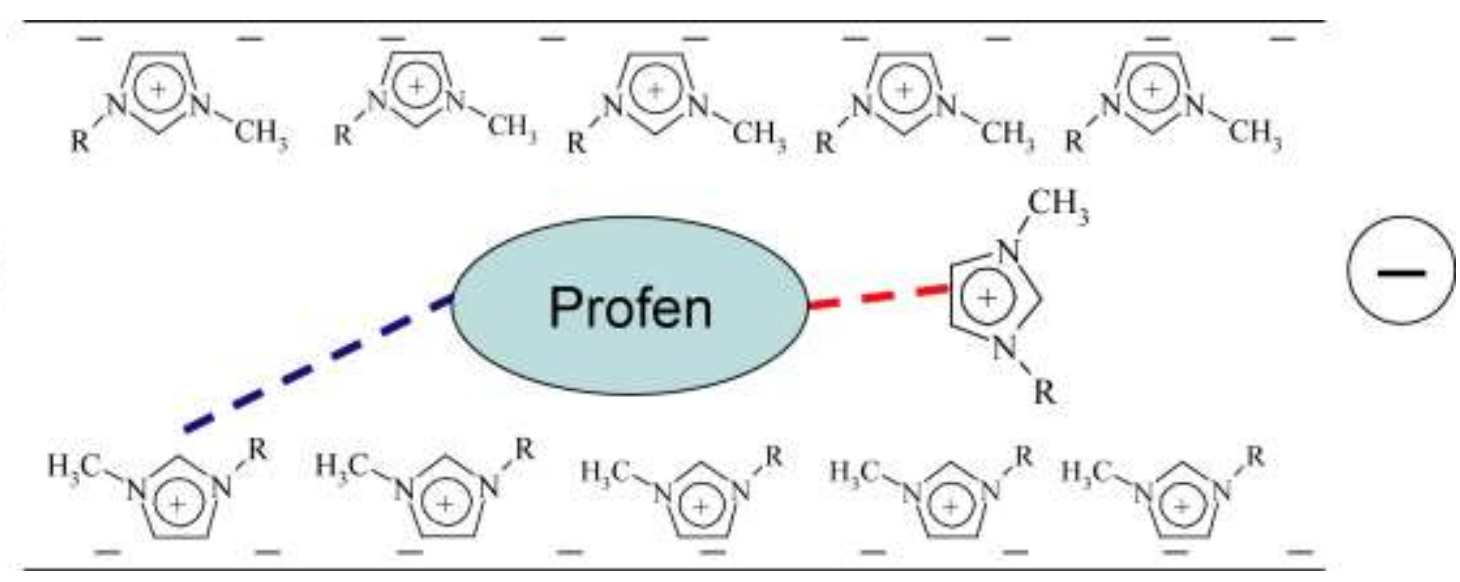

345 Figure 5: Schematic description of the competitive interactions between anionic profen and 1-

346 butyl-3-methylimidazolium cation, free in the BGE or adsorbed onto the capillary wall. $(\mathrm{R}=$ 347 Butyl group) 